\title{
NK2 Homeobox 1 Measurement
}

National Cancer Institute

\section{Source}

National Cancer Institute. NK2 Homeobox 1 Measurement. NCI Thesaurus. Code C123558.

The determination of the amount of the NKX2.1 transcription factor present in a sample. 